\title{
Recent ice age hypotheses
}

\author{
Martin Schwarzbach \\ Geologisches Institut, Universität Köln, 5000 Köln, Germany
}

Correspondence: $\quad$ Frank Preusser (frank.preusser@geologie.uni-freiburg.de)

Relevant dates: $\quad$ Published: 17 December 2021

How to cite: $\quad$ Schwarzbach, M.: Recent ice age hypotheses, DEUQUA Spec. Pub., 3, 79-86, https://doi.org/10.5194/deuquasp-3-79-2021, 2021.

Special issue statement. This article is part of a special issue published on the occasion of the 70th anniversary of $E \& G$ Quaternary Science Journal (EGQSJ). The special issue celebrates the journal's notable contribution to Quaternary research by revisiting selected milestone articles published in the long history of EGQSJ. The German Quaternary Association (DEUQUA) presents translations of the originals and critical appraisals of their impact in tandem anniversary issues of DEUQUASP and EGQSJ, respectively.

Original article: https://doi.org/10.3285/eg.19.1.21

Tribute: https://doi.org/10.5194/egqsj-70-2352021

Translators: Clare Bamford, Frank Preusser and Henrik Rother

Abstract. All theories for the explanation of the great climatic changes of the past have to consider that there are changes with long, median and short periods of time, the ratio between them being about $100000: 100: 1$. Moreover, these theories are only concerned with the last 600 million, years, i.e. with only $1 / 7$ (or less) of the history of the Earth, for we know nearly nothing about the climates of the Precambrian Age. In this article, a diagram shows what kind of theories are conceivable. There follows a critical examination of some new theories proposed since 1961 (and of some new discussions of old ones): (1) Jordan (1966), (2) Steiner (1967), (3) about radiation curves, (4) autocyclic theories of Tanner (1965) and Wilson (1964; autocyclic theories suppose an automatic mechanism for the cyclic change of glacials and interglacials; an older example for such a theory is that of Ewing and Donn, 1956, 1958), (5) the coincidence theory of
Fairbridge (1967), (6) the theory of continental drift, (7) of volcanic dust. None of these theories gives a wholly satisfactory explanation. From the present state of our knowledge, it seems likely that numerous causes contribute to generate an ice-age (as others have already supposed); which we term here the "multilateral origin of the ice-age". An important fact supporting this concept is that the climates of the whole Earth have shown relatively small changes since Precambrian times and have remained astonishingly constant in spite of great local changes between glacials and interglacials in the higher middle-latitudes. It seems possible that the change between glacials and interglacials is a particular characteristic of the Quaternary Age, and also that the factors lying behind the multilateral origin of an ice-age, act not independently but are causally connected. If so, the theory of multilateral origin would offer only a provisional explanation corresponding to the imperfect state of our present knowledge, and later on a single all-embracing causal mechanism might be found to replace the numerous ones described here.

\section{Introduction}

The ice ages or, to be more precise, major climate fluctuations in Earth's history, are primarily a field of research for geologists and - as far as the last ice age is concerned - for physical geographers. For the younger Quaternary, meteorologists have also made significant contributions. Strangely enough, however, most of the ice age hypotheses do not come from geologists or meteorologists, but from the representatives of the exact natural sciences: physicists, geophysicists and astronomers. The reason is probably not that geologists 


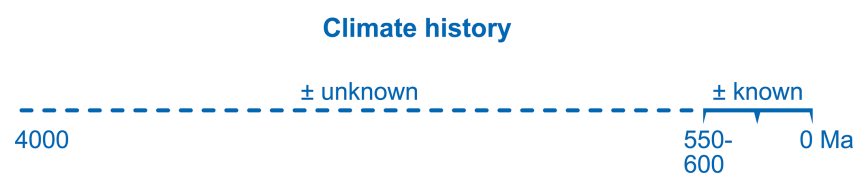

Figure 1. At best, 1/7 of Earth's climatic history is known.

lack imagination, rather that they have a better understanding than non-geologists of how uncertain and, inevitably, how incomplete geological facts of observation are. They would therefore not even dare to construct an edifice of ideas on the subject which would easily come from the mind of a scientist from afar (if one can put it that way), because the less one knows, the easier it is to form a hypothesis. A second reason lies in the fact that thoughts going beyond the factual often tend to come from neighbouring sciences.

These considerations can also be expressed in another way. The question "How to reconstruct an ice age?" is essentially answered by geologists, whereas the question "How do you construct an ice age?" by non-geologists (Shapley, 1953). The number of ice age hypotheses is still growing. A diagram I published earlier, completed by 1968, indicates that we are currently in a stage of relatively active hypothesis building.

\section{Some prerequisites for climate hypotheses}

The climate hypotheses must consider that there are climate fluctuations of very different temporal scales:

1. long-term climate fluctuations in the order of several tens of millions or 100 million years,

2. medium-term fluctuations, usually for several 10000 to 100000 years,

3. short-term fluctuations with periods of several 100 or 1000 years.

The three groups thus behave, on average over time, roughly as follows: $100000: 100: 1$. I will refrain from making a distinction between periodic climate fluctuations and more onesided climate change as this distinction is not always possible. For example, the general temperature decrease in the Tertiary appears, seen from the Quaternary period, as a climate change. However, in the context of the entire history of the Earth, it probably belongs to a climate fluctuation.

The three ice ages of the Earth's history (Quaternary, Carboniferous-Perm, Eocambrian) occurred with a repeated gap of 275 million years over the last 550-600 million years. This means that only $1 / 7$ (or even less) of the Earth's history can be surveyed from a palaeoclimatic point of view, because almost nothing is known about the climate of the Precambrian (Fig. 1). The climate hypotheses are therefore mostly only valid for the period since the late Precambrian.
Figure 2 is intended to briefly show the main ways in which climate fluctuations can be triggered. Primary solar radiation may remain constant (1-6), and even the solar radiation that reaches the Earth's surface can remain constant, and yet, only changes in the latitude of a location, for example due to continental drift, would lead to local climate change (1). The inclination of the Earth's axis can change episodically (2) or periodically and in conjunction with other elements of the Earth's orbit; this would result in the radiation curves shown in (3). The relief can change (4) or the composition of the atmosphere (such as the content of $\mathrm{CO}_{2}$ or ozone or volcanic dust; (5) or the composition of interstellar space (6). Finally, the primary solar radiation can also vary (7). There are thus many theoretical possibilities.

Only a few newer hypotheses or those that have come to the fore in recent years are picked out in the discussion below (for the period up to 1961 see the overview in Schwarzbach, 1961, 1963). The short-term climate changes of the historical period, which were investigated in detail by meteorologists in particular, were not considered.

\section{Pascual Jordan's Hypothesis}

Jordan (1966) explained the long-term climate fluctuations with a continuous decrease in solar radiation in connection with a decrease in the gravitational constant (Fig. 3). This primary cause, whose assumption goes back to Dirac ${ }^{1}$, also includes an expansion of the Earth - all in all a highly interesting thought construction. Jordan (1967) agrees with the assumption that, in the initial stage, the higher solar radiation caused a dense cloud cover, which in turn created an extremely uniform climate on Earth. This is supposed to continue until the Carbon-Perm and powerful hailstorms in the equatorial region would have produced the PermoCarboniferous glaciers there. I will merely mention Pascual Jordan's hypothesis, without going into detail again. It is - as far as it concerns the Gondwana glaciations - meteorologically implausible, contradicts geological observations and is geologically too carelessly justified (Schwarzbach, 1965a:142 ff.).

The Quaternary glaciations would have been caused differently, according to Jordan (1966), who sees their reason in passing a threshold value, thereby allowing the Milankovitch's radiation curves to gain great effectiveness. Contrary to the hypothesis of decreasing solar radiation, it should be added that solar radiation has been generally increasing since the Precambrian period, apart from individual fluctuations. This has long been advocated by the astronomer Öpik (1965).

\footnotetext{
${ }^{1}$ Translators' note: In the late 1930s, Paul Dirac promoted the hypothesis that the value of gravitational constant has continuously decreased since the formation of the universe and consequently also since the formation of the solar system and the Earth.
} 


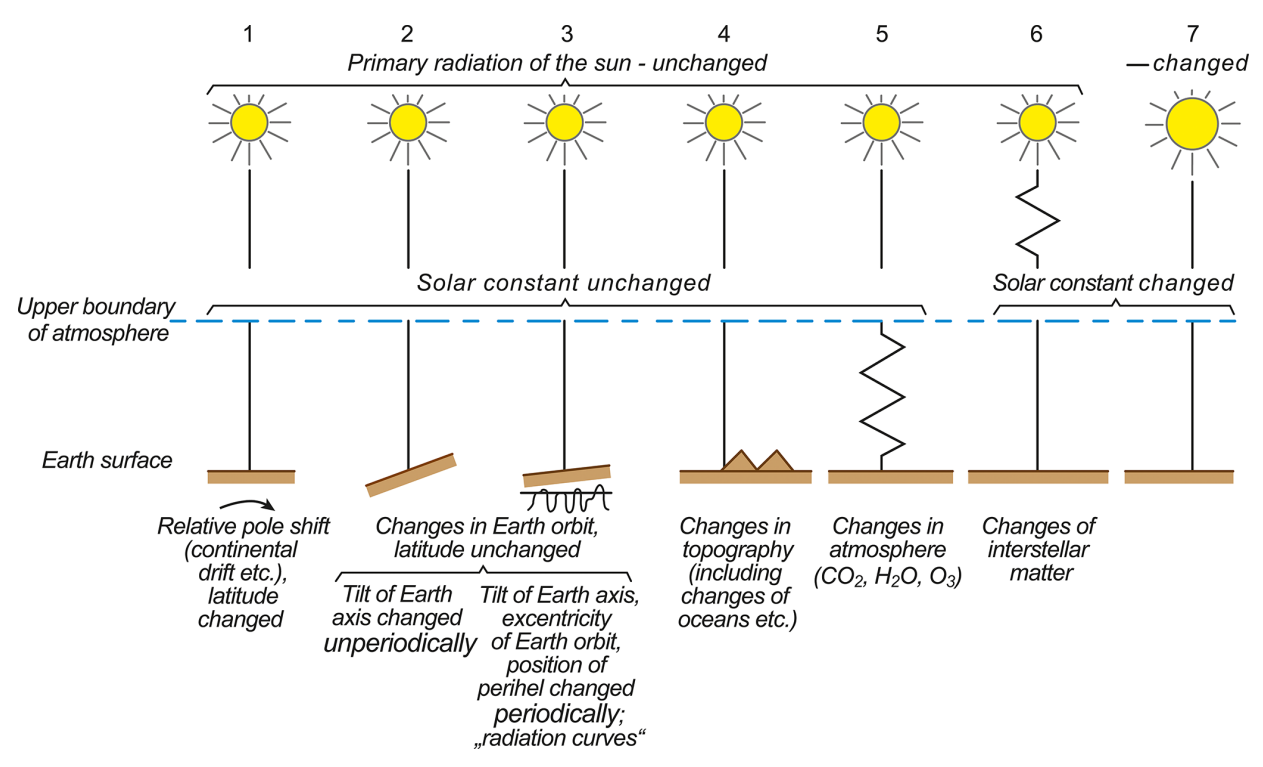

Figure 2. Possible ice-age theories. Primary radiation of the sun not changed (1-6) or changed (7); solar constant not changed (1-5) or changed (6-7). $1=$ continental drift etc., $2-3=$ orbital variations; $4=$ variations of relief, $5=$ of atmosphere, $6=$ of interstellar matter.

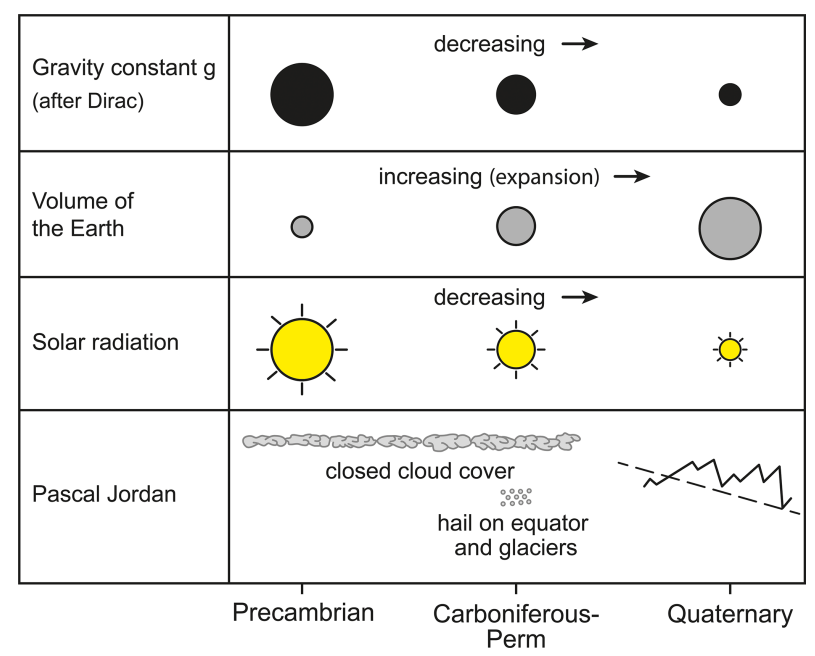

Figure 3. Pascual Jordan's hypothesis. Gravitation - constant $g$ decreasing, volume of the earth increasing, radiation of the sun decreasing; closed cloud cover till Permian.

\section{Johann Steiner's hypothesis}

A funny hypothesis, which again follows Dirac's assumption, was recently published by Steiner (1967). He too expects a change in solar radiation due to the decreasing gravitational constant, but he makes a second assumption (Fig. 4). Namely, that due to the rotation of the Milky Way system and the resulting change in the position of the solar system within the Galaxy, there is an additional change in the gravitational constant and thus an additional change in solar radiation. The rotation time is approximately - it is not possible to say exactly -280 million years. That is, it corresponds quite exactly to the time interval between the Quaternary and CarboniferousPermian Ice Ages. It is even stranger that the Eocambrian Ice Age preceded the latter ice age again by this approximate amount of time. However, Steiner (1967) did not go that far. But if one does not want to assume that the equidistant spacing of the three great ice ages is wholly coincidental, causal connections between the rotation of the galaxy and fluctuations in solar radiation, as assumed by Steiner (1967), provide a surprising and impressive explanation. Incidentally, Lungershausen ${ }^{2}$ has already pointed out the temporal parallelisms without going into these causes in greater detail. It must be added, however, that a review of the theoreticalphysical basis, as Prof. Helmut Hönl from Freiburg kindly informed me, has shown that the effect used by Steiner (1967) is probably much too small to cause significant variations in solar radiation.

\section{Latest developments on radiation curves}

The most important medium-term climate fluctuations are the change of ice and interglacial periods in the Quaternary period, i.e., a pronounced cyclical climate change. The cause can be seen in fluctuations in primary solar radiation, in a kind of "flickering" of the sun (according to Öpik, 1965). Apart from this, there are two groups of hypotheses which are particularly useful in explaining them. Firstly, the astronomical hypotheses briefly mentioned by Jordan (1966), based on

\footnotetext{
${ }^{2}$ TN: Presumably this refers to: Lungershausen, G. F.: Periodic variations of climate and great glaciations in the Earth, Sov. Geol., 18, 88-116, 1957.
} 


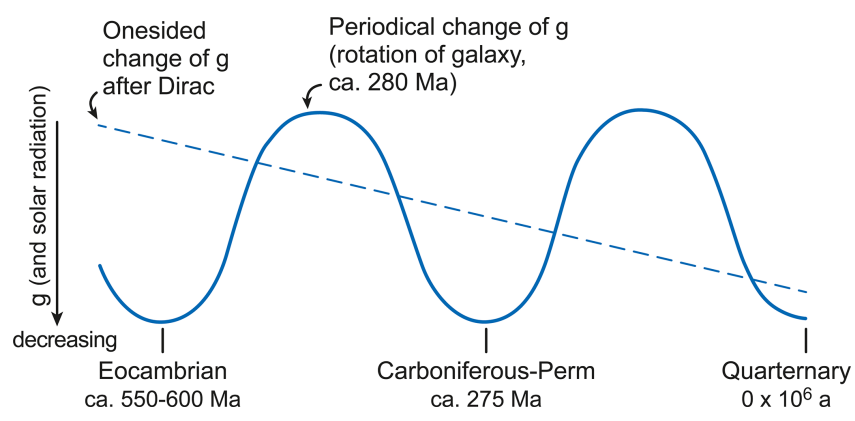

Figure 4. Johann Steiner's hypothesis (extended to the Eocambrian by the present author). One-sided and periodical variation of $g$.

the "radiation curves" of Milankovitch ${ }^{3}$. If one adds a newer celestial-mechanical additional assumption of the Hungarian Baczák $^{4}$, the radiation curve hypotheses are also valid for long-term fluctuations.

Woldstedt (1965) and others completely reject the paleoclimatological interpretation of the radiation curves, perhaps not always with very sound arguments. In contrast, Bernard (1962) tried to prove their validity for the tropical pluvials and interpluvials of Africa, and some Americans have recently started to use them again. The resulting dates, however, yield at least in part irreconcilable problems when considering other dates: Emiliani ${ }^{5}$ attributes an age of 300000 years for the Günz glaciation, Woldstedt (1965), however, assigns an age of 700000 years! Broecker (1966) tried to adapt the radiation curves better to the geological time scheme by a clever manipulation. He thought that the precession of the equinoxes should be valued higher than the change of the inclination of the earth's axis, and in this way, he could finally iron out a flaw, namely Milankovitch's radiation maximum at 48000 years, which is missing in Emiliani's temperature curves. Furthermore, he assumed (similar to earlier authors) that only changes of particularly large amplitude caused changes from glacial to interglacial conditions (and vice versa). But it must be said that the more you play around with the radiation curves, the more they fade. Indeed, it is difficult to understand why Broecker (1966) and others speak of "good agreement" between the radiation curves and the paleotemperature curves of the deep-sea sediments. Donn and Shaw (1967) were particularly critical of Emiliani's correlations, as was Öpik (1965), who, not without good reason, speaks of the "magic of coincidences".

${ }^{3} \mathrm{TN}$ : Milanković, M.: Kanon der Erdbestrahlung und seine Anwendung auf das Eiszeitenproblem, Königlich Serbische Akademie, Belgrade, Serbia, 633 pp., 1941.

${ }^{4} \mathrm{TN}$ : Presumably this refers to: Bacsák, G.: Pliozän- und Pleisozänzeitalter im Licht der Himmelsmechanik, Act. Geol. Hung., 3, 305-346, 1955.

${ }^{5} \mathrm{TN}$ : Most likely this refers to: Emiliani, C: Pleistocene temperatures, J. Geol., 63, 538-578, 1955.

\section{Autocycle hypotheses}

A second group of hypotheses for medium-term climate variability has emerged in recent years, particularly in North America. It uses an automatic mechanism whereby the growth of glaciers stops of its own accord and declines once a certain maximum is reached, and then automatically returns once a minimum is reached. These therefore resemble independently controlled cyclical processes. I would therefore like to refer to the corresponding hypotheses as autocycle hypotheses. Such hypotheses have been put forward by Ewing and Donn $(1956,1958)$ and (for $\left.\mathrm{CO}_{2}\right)$ by Plass ${ }^{6}$, among others; I have already commented on both of these earlier. Two others were put forward by Tanner (1965) and Wilson (1964).

It is interesting that the autocycles and the radiation curve hypotheses have some items in common, although their principles are completely different. Firstly, an explanation is required as to why they have become effective only since the beginning of the Quaternary period, and secondly, they, at least partly, inherently assume that either the northern or the southern hemisphere controls the climate of the whole Earth (northern hemisphere: Zeuner ${ }^{7}$ and others, with regard to the radiation curves, Ewing and Donn (1956, 1958), Tanner (1965); southern hemisphere: Wilson (1964).

Incidentally, Dorman (1968) recently pointed out that even a (long-term) cycle of $30 \times 10^{6}$ year could perhaps be explained by an autocyclic process. Dorman (1968) builds his theory based on the $\mathrm{CO}_{2}$ content of the atmosphere. But already the starting point for these considerations - the existence of a $30 \times 10^{6}$ year cycle - is not very well founded.

\section{Tanner's hypothesis}

The autocycle hypothesis of Tanner (1965) is based on the Pleistocene North European and North American inland ice and postulates that I was supplied by precipitation bearing winds mainly to its southern fringe (Fig. 5). The ice therefore flowed towards its "source". After a certain period of time, however, the advancing ice entered warmer latitudes with the growth slowing down and eventually ceasing entirely. Isostatic subsidence of the bedrock favours re-melting and prolongs the interglacial period. Only after the ground has reached its original altitude level again, will the advance begin anew. In island regions such as Greenland and Antarctica, which do not extend into warm regions, the mechanism is not effective; permanent ice sheets form there.

\footnotetext{
${ }^{6} \mathrm{TN}$ : Presumably this refers to: Plass, G. N.: The carbon dioxide theory of climate change, Tellus, 8, 140-154, 1956.

${ }^{7} \mathrm{TN}$ : This likely refers to: Zeuner, F. E.: The Pleistocene Period, 2nd edn., Hutchinson \& Co., London, UK, 447 pp., 1959.
} 


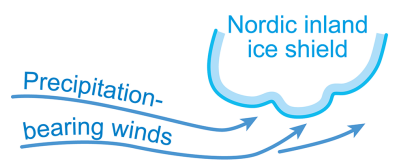

Beginning

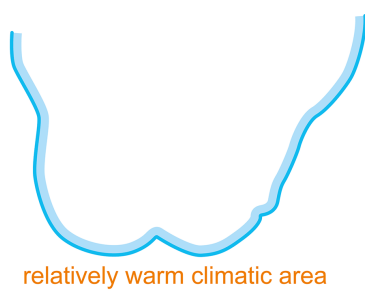

Maximum of a glacial period
Figure 5. Tanner (1965) autocyclic hypothesis. Snow-bringing winds; beginning and maximum of a Quaternary glacial.

\section{Wilson's hypothesis}

Wilson (1964) moves the engine of the ice age climate change into the exact opposite direction, to Antarctica (Fig. 6). In his opinion, the Antarctic ice sheet becomes unstable when it becomes too thick (thicker than today), because it then reaches the pressure melting point at its base. Enormous masses of shelf ice are advancing in all directions (similar to today's Ross Ice Shelf) up to the Antarctic convergence (the boundary between the $8-10^{\circ}$ warm water of the southern oceans and the much colder waters around Antarctica, which today lie at about $50^{\circ}$ south latitude). This considerably increases the albedo of the Earth surface, lowering the earth temperature, and initiating glaciation in the northern hemisphere and thus, the beginning of a glacial period. However, this state is not stable, because as for the Antarctic ice sheet the outflowing ice is at first replaced by cold ice. This leads to a drop in ice supply to the outer regions, the ice shelf breaks up by calving, leading to a decrease of albedo and an overall temperature increases - an interglacial begins. Only a large ice sheet can cause this interplay, i.e. this only could have begun when the Antarctic continent had arrived in a South Pole position. During the Tertiary period, smaller ice sheets may have caused minor cyclical movements, which may have led to cyclical sedimentation (cyclothems) in other areas. The hypothesis only works if a large ice sheet of excessive thickness really does flow apart to an extent that the ice surface increases enormously. This is hardly likely to happen - least of all in the mountainous relief of the Antarctic ice sheet.

\section{Coincidence hypothesis by Fairbridge}

For some of the autocycle hypotheses it is an essential precondition that an Antarctic continent exists (Wilson, 1964) or an Arctic Sea basin (Ewing and Donn, 1956, 1958). They even justify the occurrence of the Quaternary glaciations (as Köppen and Wegener ${ }^{8}$ did earlier) by the fact that at the end of the Tertiary this constellation was reached as a result of

\footnotetext{
${ }^{8} \mathrm{TN}$ : Presumably this refers to: Köppen, W. and Wegener, A.: Die Klimate der geologischen Vorzeit, Gebrüder Borntraeger,
}

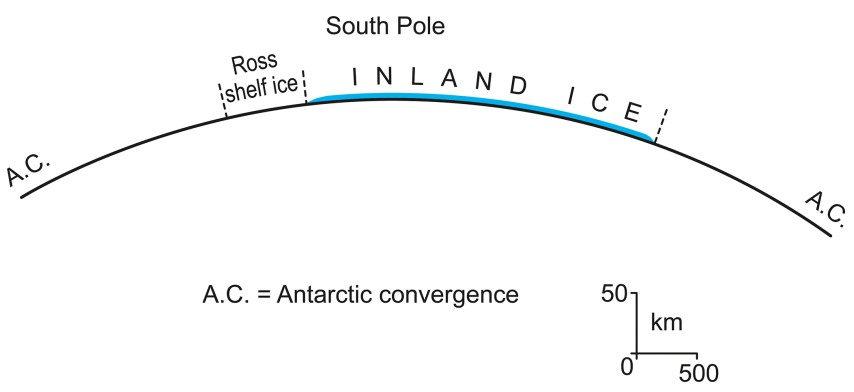

Figure 6. A. T. Wilson's hypothesis. Profile through the Antarctic inland ice and the "glacial" shelf ice, thickness of the ice $10 \times$ exaggerated. A. K. = Antarctic convergence.

continental drift. Such a drift in so recent times is hardly evidenced, neither from geological nor from palaeomagnetic records. On the other hand, the present distribution of land and sea at the two poles must certainly be of great significance for the climatic conditions (in addition to the uplift of Antarctica, which Kremp (1964) places into the late Tertiary, but without further conclusive evidence). Fairbridge (1967) has spoken of a polar coincidence theory in this context, with the coincidence of the Antarctic position playing the most important role. I would like to assume that although polar coincidence plays an important role in the Quaternary period and, for example, the permanence of the Antarctic ice, which survived repeated interglacial periods, is of crucial importance, the large, long-term climate fluctuations do not depend on it.

\section{Continental drift}

Since paleomagnetic methods have been widely developed and applied regionally, i.e., in the last 10-15 years, the continental drift hypothesis has again become the focus of interest. Because of their climatic consequences - which we already touched on above in the coincidence hypothesis - it must also be included in the ice age hypotheses. It is still controversial; Pascual Jordan recently vivaciously called it a "geophysicists' favourite fairy tale", while at two Gondwana symposia held in Mar del Plata in autumn 1967 and Montevideo, continental drift was almost never discussed, but instead is taken for granted. Geologists of the southern hemisphere were always more open to such an interpretation than their colleagues from the northern hemisphere - which are too often tied to the received opinions from - tectonists.

In any case, the correspondence between palaeomagnetically derived latitudes and the geologically reconstructed climate history is sometimes so striking that it is difficult not to believe in continental drift to be of important influence. An example is provided by Australia (compare the diagram of the Tertiary climate development of Australia and New

Stuttgart, Germany, 256 pp., 1924. Full English translation published in 2015 by Borntraeger Science Publishers. 


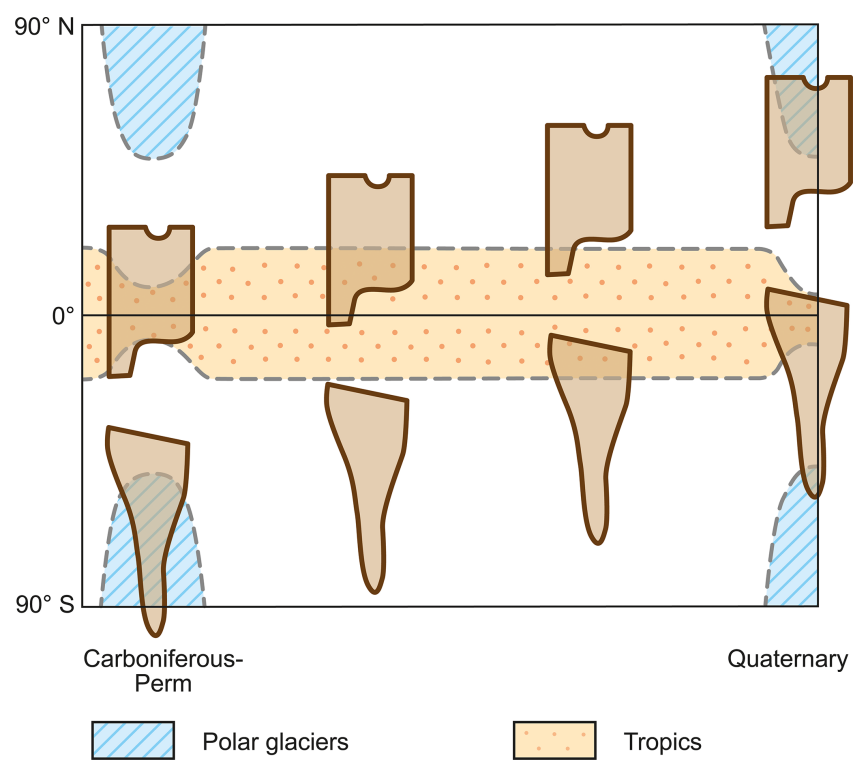

Figure 7. Continental drift of two continents (e.g., North and South America) and the corresponding climatic changes since Palaeozoic times. Polar glaciers only in Carboniferous-Permian and Quaternary times. Very schematically.

Zealand in Schwarzbach, 1965a, b). The climate history of South and North America can also be interpreted easily by drift. This is shown schematically in Fig. 7. Assuming the existence of polar glaciers in the Carboniferous Permian and Quaternary periods, it is easy to understand why glaciations of Gondwana only occured in South and not in North America, whereas the Quaternary glaciations are much more extensive in North America. For the climate history of South America see also the new compilation by Volkheimer (1967).

\section{Volcanic dust}

Until recently, volcanic dust has been counted among the likely factors contributing to the coming of an Ice Age, especially by some meteorologists. Lamb (1967) has recently even suspected that the relatively cool years after 1895 in Dunedin (New Zealand) and Punta Arenas (South Chile) are connected with the unknown disappearance of the subAntarctic volcanic Thompson Island $\left(54^{\circ} \mathrm{S}, 5^{\circ} \mathrm{E}\right)$, which may have had a catastrophic eruption.

It seems certain that large eruptions such as that of Krakatoa in 1883 caused a slight drop in temperature in places and for a short time. However, this could only be of greater climatic influence if such events were repeated at short intervals and over long periods of time. The geological observations do not provide any indication of this, although documenting the appropriated geological evidence would also be extremely difficult. What we observe in the old strata sequences are mainly lava flows, and these are unimportant as sources of dust. The (much more rarely preserved) ash layers cannot be seen to have had any influence on the weather or climate. It would be a great coincidence if our descendants, let us say after 20 illion years, would recognise the Krakatau eruption of 1883 in its full extent, or notice the Icelandic Hekla ashes of 1947 , that they were of no climatic importance.

Bloch (1964) has pointed out that volcanic ash, when falling on glaciers, accelerates their melting, suggesting that this has caused Quaternary climate variations. However, even the area of the ash regions is probably far too small, for example, compared with the area of Antarctic ice, to have an Earth-wide effect.

\section{Multilateral ice age formation}

Although most ice age hypotheses assume some specific factor as the main cause, and have corresponding names $\left(\mathrm{CO}_{2}\right.$ hypothesis, etc.), additional conditions are often used. Milankovitch's radiation curves, for example, which, according to Köppen, Wegener, and others only led to ice ages when a second event led to a general temperature decrease. In general, a large number of the ice age hypotheses explain only parts of the earth's climate history, and not a single one provides a fully valid, rounded explanation. This is a somewhat unsatisfactory conclusion.

Perhaps the key lies in the fact that the major climatic changes in the history of the earth have a number of causes. I would call this multilateral ice age formation.

This is particularly true if, for once we do not focus on the climate contrasts over the course of the Earth's history, which are certainly present, but instead on the even more conspicuous, but mostly unnoticed, constancy of our climate. Of course, we must not take as our starting point the countries in which almost all ice age hypotheses originated, i.e., not Europe and North America. For these are exceptional areas, "sensitive latitudes", as Fairbridge (1967) aptly called them, which were still glaciated during the Pleistocene. Here, the Quaternary is characterised by truly profound climate fluctuations, and in addition the period at least from the Middle Palaeozoic to the Early Tertiary had much higher temperatures than today. Both of course mean very large temperature contrasts within the course of the Earth's history - in Germany for example an annual average temperature of about $25^{\circ} \mathrm{C}$ during the Devonian but only $0{ }^{\circ} \mathrm{C}$ during the Würm glacial -, and we are inclined to consider this to be the norm for the whole earth. But this is not the case, and the noted large differences lose their weight when compared to the situation at lower latitudes, where the Pleistocene glacials had little influence on the climate curve. Furthermore, the possibility of continental drift or other latitudinal changes has to be taken into account, especially for the ancient history of the earth. But let leave aside those special cases that we are familiar with and compare global average temperatures. Flohn (1965) and others have provided the following estimates: 
- Today: $15.5^{\circ} \mathrm{C}$

- Quaternary glacials: $11^{\circ} \mathrm{C}$

- Ice-free periods during Earth's history: $23-24{ }^{\circ} \mathrm{C}$

The total temperature fluctuation over the last 600 million years is then not $25^{\circ} \mathrm{C}$, but no more than $12-13{ }^{\circ} \mathrm{C}$. By far the greatest changes occurred in the polar regions. The overall climate of the Earth has therefore remained astonishingly constant, and the palaeoclimatologist should actually not only be concerned with climate fluctuations, but also with the phenomenon of climate constancy. The relative insignificance of climate variability is also confirmed by the evolution of the flora and fauna: it has been so continuous that it has been described as a "principle of biological continuity". This can only be due to the fact that since the Pre-Cambrian period the main living areas of organisms have been characterised thermally in much the same way as they are today. Catastrophic climatic events never really intervened in the organic life. At present, almost all organisms live at temperatures with an average between +5 and $+35^{\circ} \mathrm{C}$ in July and an annual average between -15 and $+30^{\circ} \mathrm{C}$. These values have obviously not been significantly exceeded or undercut during this long period.

Ultimately, therefore, the sun's radiant power must have remained roughly constant over hundreds of millions of years. This does not exclude minor fluctuations in primary solar radiation. These may be compounded by the many other factors indicated by the various ice age hypotheses, which may influence the climate on different scales: the profound geographical changes in the distribution of land and sea and in the relief, i.e., the constantly changing face of the Earth, changes in the $\mathrm{CO}_{2}$ and water vapour content of the atmosphere, periodic changes in the elements of the Earth's orbit, dark clouds in space, but also continental drift and many others. The interaction of all these factors would be the cause of the small and large climate fluctuations in the Earth's history in the sense of a multilateral ice age development.

The initial formation of larger ice masses in the polar region certainly plays a decisive role due to the secondary cooling or "self-reinforcing" effects that are automatically coupled with it. As it appears, this has happened rarely, and thus extended cold periods are very rare in the Earth's record. It may then depend on the random palaeogeographical conditions, such as the "Antarctic coincidence", which determine how such an ice age will develop specifically. It could be that the change of glacials and interglacials, so familiar to Quaternary geologists, is a peculiarity of the Quaternary period, because the permo-Carboniferous Gondwana glaciations have not yet been identified to have had the same order of magnitude, and even less so during the Eocambrian Ice Age. Of course, this may be based on incomplete records. In the case of the Eocambrian, the "Tillites" of the Eocambrian are not entirely confirmed and recently (Olson, 1966) have all been interpreted as non-glacial formations in connection with the "lunar detachment" (which, of course, hardly any geophysicist would place into such a young time!).

The assumption of multilateral ice age formation represented here is an extension of ideas that other researchers have already put forward, such as the English meteorologist Brooks in his "Climate through the Ages". However, unlike Brooks (1949) and some more recent meteorologists, including Lamb (1967), I consider volcanic dust to be a minor issue, but I would like to add two factors: primary variations in solar radiation - albeit of relatively small magnitude (as Richard Foster Flint ${ }^{9}$ does in his "solar-topographic hypothesis") - and continental drift (or at least pole wander).

The Quaternary climate history remains a special chapter, at least for the time being. Whether autocyclic processes dominate here remains unknown for the time being, but one must be prepared for the possibility that long-term and medium-term climate fluctuations may occur relatively independently of each other.

The more causes one assumes, the more difficult it becomes to recognise and to explain any long-term periodicities in climate history, i.e., whether they are based on chance or not. Some of the numerous factors may be causally linked (e.g., $\mathrm{CO}_{2}$ content with volcanic processes or with mountain erosion or coal formation), but not much can be said about them, at least quantitatively.

It is even conceivable that not only some, but all factors in the multilateral ice age development are causally linked, and that everything or almost everything can be traced back to a single, overriding cause. The Ice Age would then only appear to be multilateral, and the hypothesis would be a kind of provisional explanation, in line with the current, imperfect state of our knowledge. It would then perhaps one day make way for a comprehensive ice age hypothesis. Steiner (1967), for example, has made some attempts in this direction, but for the time being they are far too hypothetical to provide a satisfactory solution at this stage.

Review statement. This paper was edited by Frank Preusser.

\section{References}

Bernard, A. E.: Theorie astronomique des pluviaux et interpluviaux du Quaternaire africain, Mem. Acad. roy. Sei. d'Outre-Mer, Cl. Sei. nat.-med., n. s. 12, 1-232, Bruxelles, Belgium, 1962.

Bloch, M. R.: Die Beeinflussung der Albedo von Eisflächen durch Staub und ihre Wirkung auf Ozeanhöhe und Klima, Geol. Rundsch., 54, 515-522, https://doi.org/10.1007/BF01821200, 1964.

Broecker, W. S.: Absolute dating and the astronomical theory of glaciation, Science, 151, 299-304, https://doi.org/10.1126/science.151.3708.299, 1966.

\footnotetext{
${ }^{9}$ TN: Most likely this refers to: Flint, R. F.: Glacial Geology and the Pleistocene Epoch, Wiley \& Sons, London, UK, 589 pp., 1947.
} 
Brooks, C. E. P.: Climate through the ages, 2nd edn., Ernest Benn Ltd, London, UK, 395 pp., 1949.

Donn, W. L. and Shaw, D. M.: The generalized temperature curve for the past 425000 years: a discussion, J. Geol., 75, 497-503, https://doi.org/10.1086/627275, 1967 (reply by C. Emiliani ibid. 504-509).

Dorman, F. H.: Some Australian oxygen isotope temperatures and a theory for a 30-million-year world-temperature cycle, J. Geol., 76, 297-313, https://doi.org/10.1086/627330, 1968.

Ewing, M. and Donn, W.L.: A Theory of Ice Ages, Science, 123, 1061-1066, 1956.

Ewing, M. and Donn, W.L.: A Theory of Ice Ages II, Science, 127, 1159-1161, 1958.

Fairbridge, R. W.: Ice-age theory, in: The encyclopedia of atmospheric sciences and astrogeology, 1st edn., edited by: Fairbridge, R. W., Reinhold, New York, USA, 462-474, 1200 pp., 1967.

Flohn, H.: Grundfragen der Paläoklimatologie im Lichte einer theoretischen Klimatologie, Geol. Rundsch., 54, 504-515, https://doi.org/10.1007/BF01821199, 1965.

Jordan, P.: Die Expansion der Erde, 1st edn., edited by: Westphal, W. and Rotta, H., Vieweg \& Sohn, Braunschweig, Germany, 182 pp., 1966.

Jordan, P.: Über die Wolkenhülle der Venus, 1st edn., Steiner, Wiesbaden, Germany, 43-54, 1967.

Kremp, G. O. W.: Antarctica, the climate of the Tertiary, and a possible cause for our Ice Age, Interim Res. Rep. 2, 1-18, Geochron. Labor., Tuscon, USA, 1964.

Lamb, H. H.: The problem of "Thompson Island": volcanic eruptions and meteorological evidence, Brit. Antarct. Surv. B., 13, 85-88, 1967.
Olson, W. S.: Origin of the Cambrian-Precambrian unconformity, Amer. Scient. 54, 458-464, 1966.

Öpik, E. J.: Climatic change in cosmic perspective, Icarus, 4, 289307, https://doi.org/10.1016/0019-1035(65)90006-0, 1965.

Schwarzbach, M.: Das Klima der Vorzeit, 2nd edn., Verlag Ferdinand Enke, Stuttgart, Germany, 275 pp., 1961.

Schwarzbach, M.: Climates of the Past, D. Van Nostrand Co., London, UK, 328 pp., 1963.

Schwarzbach, M.: Paläoklimatologische Eindrücke aus Australien, Geol. Rdsch., 54, 128-160, 1965a.

Schwarzbach, M.: Paläoklimatologische Eindrücke aus Neuseeland, E\&G Quaternary Sci. J., 16, 226-238, https://doi.org/10.3285/eg.16.1.16, 1965 b.

Shapley, H.: Climatic Change, Harvard University Press, London, UK, 318 pp., 1953.

Steiner, J.: The sequence of geological events and the dynamics of the milky way galaxy, J. Geol. Soc. Austral., 14, 99-131, 1967.

Tanner, W. F.: Cause and development of an ice age, J. Geol., 73, 413-430, 1965.

Volkheimer, W.: Palaeoclimatic evolution in Argentina and relations with other regions of Gondwana, Simposio internac. estratigr. paleont. Gondwana, 1-15 October 1967, La Plata, Argentina, 1967.

Wilson, A. T.: Origin of ice-ages: an ice shelf theory for pleistocene glaciation, Nature, 201, 147-149, 1964.

Woldstedt, P.: Die interglazialen marinen Strände und der Aufbau des antarktischen Inlandeises, E\&G Quaternary Sci. J., 16, 3136, https://doi.org/10.3285/eg.16.1.02, 1965. 